\title{
The Gap Concept as a Quality of Life Measure: Validation Study of the Child Quality of Life Systemic Inventory
}

\author{
Anne-Marie Etienne • Gilles Dupuis • Elisabeth Spitz • \\ Fabienne Lemetayer $\cdot$ Pierre Missotten
}

Accepted: 24 March 2010/Published online: 7 April 2010

(C) Springer Science+Business Media B.V. 2010

\begin{abstract}
The objective was to determine the interest and psychometric properties of a new QOL self-assessment questionnaire suitable for children 8-12 years old measuring alpha, beta and gamma changes: the "Inventaire Systémique de Qualité de vie pour Enfants" (ISQV-E ${ }^{\odot}$ ). This was a cross-sectional validation study. 288 children have completed the ISQV-E. Other tools were used: The "Autoquestionnaire de Qualité de Vie Enfants Imagé" (AUQUEI), the State-Trait Anxiety Inventory for Children (STAIC), the Children's Depression Inventory (CDI). The internal consistency of the four scores of the ISQV-E (state, goal, rank and gap) is satisfactory. All scores have their own specificity. The data show the convergent validity, sensitivity and applicability of the ISQV-E. On the other hand, no satisfactory factorial structure was found although a multidimensional theoretical perspective was applied. The feasibility of the ISQV-E seems clearly demonstrated and the value of this new tool seems evident in contexts of physical, psychological or social problems. The validation study was promising but certain points such as test-retest reliability remain to be studied.
\end{abstract}

Keywords Quality of life · Child · Validation studies · Questionnaires

\author{
Abbreviations \\ QoL \\ Quality of life \\ ISQV-E \\ Inventaire Systémique de Qualité de Vie-Enfant
}

\author{
A.-M. Etienne $(\bowtie)$ \\ University of Liege, Liège, Belgium \\ e-mail: AM.Etienne@ulg.ac.be \\ G. Dupuis \\ University of Quebec to Montreal, Montreal, Canada \\ E. Spitz - F. Lemetayer \\ University of Paul Verlaine, Metz, France \\ P. Missotten \\ CHR Citadelle, Liège, Belgium
}




$\begin{array}{ll}\text { EHRQL } & \text { Exeter health-related quality of life questionnaire } \\ \text { HAY } & \text { How are you questionnaire } \\ \text { PedsQL } & \text { Pediatric quality of life inventory } \\ \text { TACQOL TNO AZL } & \text { Children's quality of life } \\ \text { QLSI } & \text { Quality of life systemic inventory } \\ \text { AUQUEI } & \text { Autoquestionnaire de Qualité de Vie Enfants Imagé } \\ \text { STAIC } & \text { State-trait anxiety inventory for children } \\ \text { CDI } & \text { Children's depression inventory } \\ \text { KidlQol } & \text { Pediatric quality of life inventory generic core scales }\end{array}$

\section{Background}

Quality of life (QoL) has only recently been studied in children and is still less studied than adult QoL (Ravens-Sieberer et al. 2006; Wallander et al. 2001). In all contexts (physical, psychological or social problems), the assessment of children's QoL involves taking into account their status as subject who are constantly changing and developing (Blanchon 1997).

This specificity makes us think about which type of assessment to apply: a self- or proxy-report? This interrogation has not yet found categorical answer (Speyer et al. 2009). It seems that agreement between self-report and proxy is greater for some domains than for others. Several studies showed better agreement for physical function than for social and mental domains (Eiser and Morse 2001a, b, c; Fluchel et al. 2008; Yeh et al. 2005), whereas others showed the contrary (Czyzewski et al. 1994; Theunissen et al. 1998). At present, children are considered to be the best persons to express the perception they have of their own QOL (Eiser 1997; Harding 2001; Siméoni et al. 1999; Theunissen et al. 1998; Varni et al. 2005), especially since QOL measures are no longer simple statements of functional information. To support the choice of the self-assessment, numerous authors (Eiser 1997; Harding 2001; Siméoni et al. 1999; Theunissen et al. 1998; Varni et al. 2005; Wallander et al. 2001) make reference to the absence or to little of concordances demonstrated between the self- and the proxy-report (by proxies of children affected by chronic diseases and healthy children).

Therefore, choosing for self-assessment requires taking developmental considerations into account, such as developmental differences in the QoL criteria, the child's level of cognitive development and attention capacities, the child's dependence and his capacity to describe his state of satisfaction (Missotten et al. 2007). Consequently, attempting to apply a single QoL assessment tool for children of different ages is both difficult and inappropriate. One strategy is to create multiple forms of a child-report QoL instrument, each designed for a different age group. These forms vary in their content, length, the proposed response scale and the independence required to complete them (Matza et al. 2004; Wallander et al. 2001).

The aim of this article is to report the development of a new QoL self-assessment questionnaire suitable for children 8-12 years old, the Inventaire Systémique de Qualité de Vie-Enfant, ISQV-E ${ }^{\circledR}$ (in English's: Child Quality of Life Systemic Inventory). While the concepts of goals, expectations, standards, and concerns are core elements of the World Health Organization's QoL definition (WHOQOL Group 1993), no previous child-focused tool has included these notions. A review of the QoL questionnaires (Bullinger and 
Ravens-Sieberer 1995; Connolly and Johnson 1999; Davis et al. 2006; Eiser and Morse 2001a, b; Levi and Drotar 1998; Matza et al. 2004; Raat et al. 2006; Schmidt et al. 2002; Spieth and Harris 1996) show that the tools estimate this concept in terms of current state without consideration of the children's expectations. Only the Exeter Health-Related Quality of Life questionnaire (EHRQL) (Eiser et al. 1999, 2000) views QoL as "the difference, at a particular period of time, between the hopes and expectations of the individual and the individual's experience". The absence of interest in children's personal goals is coupled with a lack of concern for their priorities. Only the How Are You questionnaire (HAY) (Bruil 1999; Maes and Bruil 1995) contains a measure of the prevalence of activities or problems and their importance (assessed as feelings about problems in the quality of performance of tasks/activities). In conclusion, no child QoL questionnaire measures alpha, beta and gamma changes (Golembiewski et al. 1976) nevertheless considered as fundamental (Allison et al. 1997).

An alpha change is a change in a person's: for example, body temperature in absence of fewer). A beta change is a change in a person's condition in his goal setting: for example, a child may mention that before the dental surgeon's examination, the pain he (she) felt was the most terrible he (she) has ever felt. Now suppose that the dental surgeon does an injection, and has induced, for a short time, an even more terrible pain. The fact that the pain reported after the injection is "less" may be a result of the treatment but also because of the fact that the referring point of the most terrible pain ever felt has changed. A gamma change is a change in a person's condition in his goal setting plus a change in life priorities. For example, a girl who has lived with chronic pain such as splitting headaches may feel that to be totally free of pain is not so important. Therefore, the rating she will give to her actual pain will be less than one she would have given at the beginning of her problem. This shift, due to adaptation, makes her evaluate her state of pain as less intolerable (Dupuis et al. 2000).

The development of a new instrument able to detect alpha, beta and gamma changes further refines our understanding of children's QoL and should better capture what they are going through in the process of adapting to various problems or diseases. On the basis of these conceptual reflections, we wished that the developed questionnaire considers the QOL in terms of gap with apprehension of the concepts of personal goals and priorities (Calman 1984). Its theoretical structure had to allow the addition of specific modules to the generic core scale when appropriate. This modular perspective is at present encouraged (Eiser and Morse 2001a; Eiser and Jenney 2007; Nathan et al. 2004) because it allows combining the respective advantages of both types of usual tools (generic and specific). Few modular instruments exist: the Pediatric Quality of Life Inventory (PedsQL) has a generic scale (Varni et al. 2001) and different specific scales (Varni et al. 2001, 2002a, b, 2003, 2004a, b), the HAY (Bruil 1999; Maes and Bruil 1995), the TNO AZL Children's Quality of Life (TACQOL) has a specific asthma module (Flapper et al. 2006) and the KIDSCREEN [generic scale, Herdman et al. 2002; Ravens-Sieberer et al. 2007)/DISABKIDS has seven specific modules (Baars et al. 2005).

With this in mind, we based our work on the theoretical model and QoL definition in the Quality of Life Systemic Inventory $\left(\mathrm{QLSI}^{\odot}\right.$ ), a self-assessment QoL questionnaire (Dupuis et al. 1989; Duquette et al. 1994). These authors were inspired by the systemic approach on biologic systems from Bertalanffy's work (1973) and by the works of Ashby (1956), Weiner (1948) and Powers (1973) on cybernetics. Dupuis et al. (2000) base themselves on the Aristotelian notion of happiness in developing their definition of QOL. Thus, they say that all human activities are oriented towards an end (a goal), that certain ends (goals) are subordinated to others but that the ultimate end (goal) is the pursuit of happiness. It should 


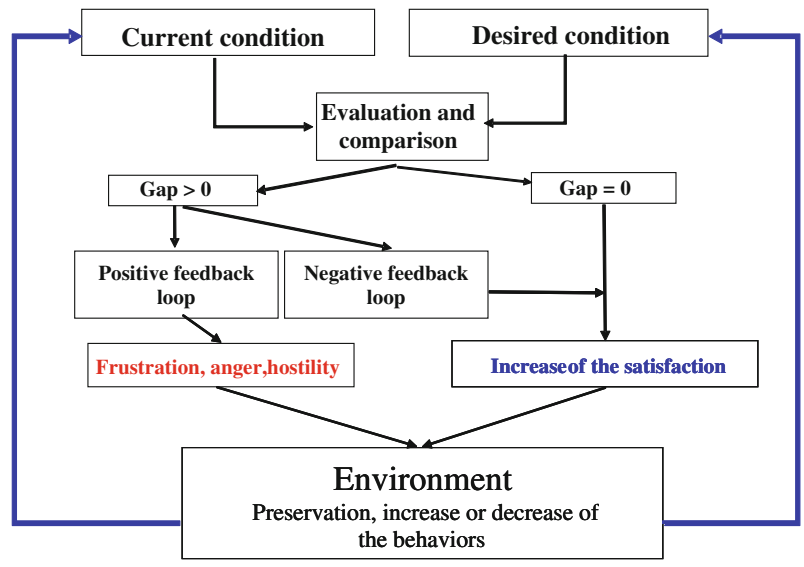

Fig. 1 Model of the mechanism for achieving goals and the immediate psychological consequences of non achievement of goals (adapted from Dupuis et al. 2000)

be emphasized that happiness connotes here not the search for pleasure or hedonistic satisfaction but a relatively stable condition over time, influenced by the individual's adaptability and a minimum of material goods.

The basic idea is that behaviors are controlled by goal-setting and are always goaldirected (Fig. 1). In such a control system, behaviors aim to reduce the gap (negative feedback loop) between the state and the goal, while taking into account the fact that these goals do not all have the same importance, that is, the same priority or value. Sometimes, a loss of control is noticed and the behaviors the subject carries out to approach a goal actually cause her to move away from it (positive feedback loop).

Finally, in their model, Dupuis et al. (2000) distinguish between factors that may influence QoL (e.g. medical condition, psychological state, economic status) and QoL as such, which is defined by the gap between the individual's current condition and his or her objectives. Dupuis et al. (1989) have defined QoL as follow: "QoL is, at a given time, a state that corresponds to the level attained by a person in his pursuit of hierarchically organized goals".

In light of these theoretical elements, the first aim of this article was to explore the feasibility of the ISQV-E: is it possible to determine children's QoL by a self-assessment questionnaire measuring alpha, beta and gamma changes? The second aim was to determine the psychometric properties of this new tool: applicability, sensitivity, reliability and validity.

\section{Methods}

\subsection{Sample}

A sample of Belgian and French children from 8 to 12 years old was requested to participate in this cross-sectional study. All of them are healthy, schooled and usually speak French.

It is a convenience sample. The recruitment was carried out within various Belgian (5 schools from Liege area) and French schools (3 schools from Metz area). They are 
representative of private and public communities. The lower age limit of 8 years is based on the work of Rebok et al. (2001) concerning the notion of time, that of Matza et al. (2004) about the duration of mobilization of attention, and that of Manificat and Dazord (1997) concerning children's capacity to assess and describe their state of satisfaction. In the view of these authors, it is only at 7 or 8 years old that children become able to judge a set of similar situations and bring out the mean emotional tone. Before that age, the point of view expressed by the child is clearly situated in the present moment. The existence of an upper limit (12 years) takes developmental specificity (content, material, etc.) into consideration.

The parents received a letter explaining the study. Signed informed consent forms from the parents and the children were required before enrolling children in the study.

\subsection{Instruments and Measures}

\subsubsection{The «Inventaire Systémique de Qualité de Vie-Enfant»}

The $I S Q V-E$ is a QOL interview-like-questionnaire specifically developed for children aged $8-12$, that needs assistance of an interviewer.

It measures the gap that exists between a child's current condition and his goals; this gap is weighted by the importance of each area of life and the dynamics of moving either closer to or farther from the goals. This instrument includes 20 domains of life, which were chosen following a review of the literature [for more details, see 9]. They cover the child's physical, emotional, cognitive, social and family functioning (Calaminus et al. 2000). Each domain is presented in both words and pictures (Fig. 2).

The questionnaire consists of three wooden boards (Fig. 3).

On the first board, a "Visual Analog Scale" (VAS) representing a circle (or a dial) with a color gradation from pale yellow (best possible situation) to red (worst possible situation) is presented to the child. Outside and inside this VAS, there are faces expressing different emotional states (from happy faces to sad faces). Using two rotating arrows, the child indicates his/her current state ("How happy is she?") with the full arrow (State score) and his/her personal goal ("Where should he/she be situated to be satisfied"?) with the dotted arrow (Goal score).

The gap score is the difference between the state score and the goal score (first board) weighted by the speed of improvement or deterioration (second board, see below) and the item's rank (third board, see below). Therefore, the test scores present us with not only their state and goal but also the distance (gap) between their condition and goal.

The dial more easily captures the visual aspect of the distance between the desired goal and its ideal than a Likert scale or a ladder would permit. We also feel that the dial (with the placement of the arrows) is a more interactive approach to measurement for both the child being tested and clinician. This is more attractive and illustrates the gap measurement more clearly.

Fig. 2 Illustration of the double presentation of each item for the first domain: sleep

\begin{tabular}{|l|c|}
\hline Word: & Picture \\
\hline SLEEP & \\
\hline
\end{tabular}



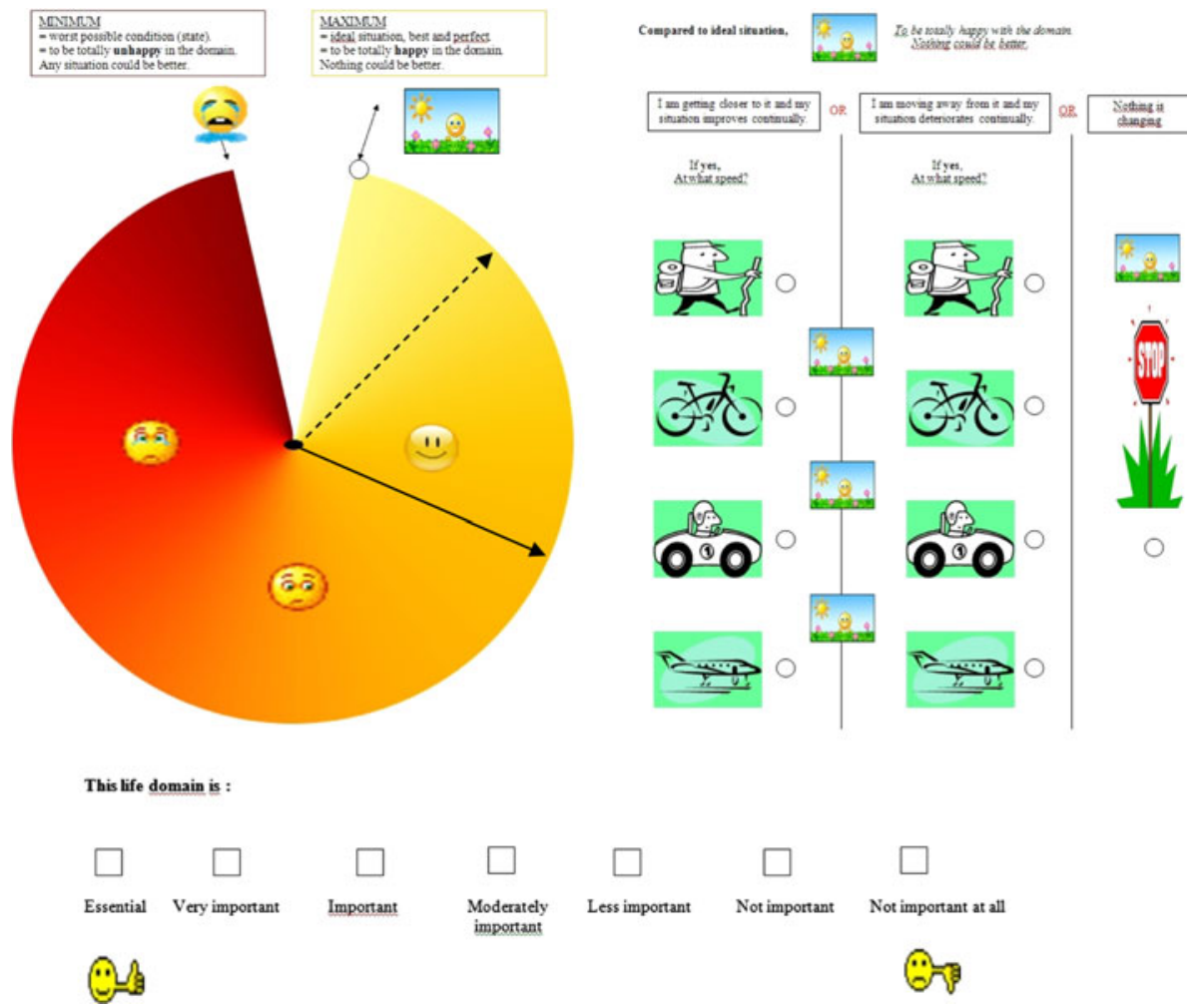

Fig. 3 Format of the «Inventaire Systémique de Qualité de Vie pour Enfants» (ISQV-E ${ }^{\odot}$ )

On the second board, the child indicates whether she thinks that, in the last few days, her current situation has been stable or is moving closer to ("Getting better and better.") or away from ("Getting worse and worse") the ideal situation. The speed dial is designed to provide information on the speed process of improvement or deterioration. If the situation is improving or deteriorating, the child has to specify the speed of improvement or deterioration. Four possibilities are offered, using four pictures: a walker, a cyclist, a car and a plane.

Finally, the third board allows the child to indicate, on a 7-point Likert scale, how important each domain is to her. A low priority life domain may not have much effect on the overall QoL, whereas any changes in an essential sphere will have quite an impact. This last scale also points out children with many high priorities which may the cause of conflicts and overpressure (Duquette et al. 1994) (Rank score).

Finally, we are aware that choosing to evaluate the gap between what the child has and what he (she) wants focus on what Michalos (1985) named the "aspiration theory", one of the seven perceived discrepancies he described. However, for simplicity of measurement with the child and also because the main objective of the measurement is the evaluation of the gap, knowing that in the personal goal setting, it is possible that some social, equity, etc. factors may colored this goal setting, we choose not to include the measurement of the different perceived discrepancies.

A completed ISQV-E is analyzed by a program similar to that finalized by Professor Gilles Dupuis for the QLSI. Based on the definition given earlier in the text and on the basic concepts of control system analysis, the measurement strategy must consider the 
evaluation of the current state and goals of an individual in different life domains. The dynamics of the patient's situation should also be considered by evaluating the speed of the improvement or deterioration. Finally, the rank of importance accorded to each life domain must be evaluated. The gap score corresponds to the mean gap between the state and the goal weighted by the dynamics and the rank, and it represents the QoL score.

Therefore, beside the gap score that represents the quality of life score, the ISQV-E provides three other indices: State, Goal, and Rank scores (Duquette et al. 1994).

- State score (0 to 100) = Mean distance between current state and ideal situation. It provides information about the actual level of happiness. The higher the mean score, the farther the current state is from the ideal.

- Goal score (0 to 100) = Mean distance between goal and ideal situation. It provides information about the desired level of happiness. The higher the mean score, the farther the goal is from the ideal.

- Gap score ( -100 to 100) = Mean distance between current state and goal, weighted by the speed of improvement or deterioration and the item's rank $\rightarrow$ QoL score. The improvement reducing (1-0.31) the subjective load of the gap because the situation is improving and the deterioration amplifying (1-3.25) the subjective load of the gap. Higher priority amplifying the gap while a lower one reduces it. The higher the mean gap score, the lower the QoL is. A negative score indicates that the current state is better that the goal.

- Rank score (2 to 0.15$)=$ Mean rank of the 20 domains. It reflects priority assigned to these various areas of life. The higher the mean rank score, the greater the level of importance is.

The basis assumption for this scaling is that the processes behind the gap, the dynamics and the hierarchy are exponential. The dial (state/goal dial gap) was divided into 13 sectors. These values were obtained from a theoretical exponential function $\left(2^{\mathrm{x}}\right)$ for which ' $x$ ' exponentially increases the number of degree per sector from 0 to 360 in 13 steps. The sectors were then rescaled from 0 to 100 to facilitate the interpretation.

\subsubsection{The «Autoquestionnaire de Qualité de Vie Enfants Imagé»}

The Autoquestionnaire de Qualité de Vie Enfants Imagé (AUQUEI) (Manificat and Dazord 1997 ) is a valid generic QOL questionnaire developed from the point of view of children, with a focus on their health (Harding 2001; Rodary 2000). It is intended for children aged 4-12 years and consists of two parts. The first is an open-ended question asking the children to relate a situation when they were very happy, happy, unhappy, and very unhappy. The second contains 26 items covering family life, social life, children's activities (school and leisure), health, bodily functions (sleep, food) and separation. For each question, four satisfaction levels are presented, ranging from 0 ("very dissatisfied") to 3 ("very satisfied"). The score of every item varies from 0 ("very dissatisfied") to 3 ("very satisfied"). The total score ranges from 0 to 78 , a high total score indicates a high level of quality of life. Only the answers to the second part will be envisaged in the present study.

\subsubsection{The State-Trait Anxiety Inventory for Children}

State-Trait Anxiety Inventory for Children (STAIC) is a self-assessment questionnaire specifically created for children aged from 8 to 12 (Spielberger et al. 1973). The State scale consists of 20 items measured with a 3-point Likert scale that assess anxiety as a fleeting 
emotional state (Georges and Vera 1999). The total score ranges from 20 to 60; a high total score indicates a high level of state anxiety.

\subsubsection{The Children's Depression Inventory}

The Children's Depression Inventory (CDI) is a 27-item, self-rating, symptom-oriented scale originally created for youths aged 8-13 (Kovacs and Beck 1977). It was translated and validated in French (Mack and Morr 1982). For each item, the child is asked to select one of the three statements that best describes his feelings for the past 2 weeks. The total score ranges from 0 to 54; a high total score indicates a high level of depression.

\subsubsection{The Socio-Demographic Data}

Socio-demographic data were also used. These included age, gender, repeating a grade (or not), social network ( $<5$ friends, 6-15 friends, $>15$ friends), existence of regular medical follow-up (or not), place of residence (city or country), type of house (apartment or house), and family composition (parents married, separated or divorced; living with sibling or not).

\subsubsection{Procedure}

Each child was assessed, individually in a classroom, by an adult interviewer. The sequence of test administration was the same for all children: first socio-demographic data, then STAI, CDI, AUQUEI and ISQV-E.

\subsection{Statistical Analysis}

The applicability of the ISQV-E was established on the basis of the number of subjects who answered every item, the time it took to complete the questionnaire and the children's interest in the task. Internal consistency reliability was determined by calculating Cronbach's alpha. Intercorrelations between the ISQV-E scores were measured with the Bravais-Pearson $r$ to study the specificity of each individual score. Factorial validity was studied with an explanatory factor analysis with extraction of principal components (with Varimax rotation) carried out on the gap scores to determine the groupings of the various items according to their correlation.

Regarding the "number of subjects"/item ratio, Tabachnick and Fidell (2001, p. 588) recommendation is: 50 cases is very poor, 100 is poor, 200 is fair, 300 is good, 500 is very good and 1,000 or more is excellent. As a rule of thumb, a bare minimum of 10 observations per variable is necessary to avoid computational difficulties.

Convergent validity was established by studying correlations between the ISQV-E and AUQUEI but also between the ISQV-E and the questionnaires on emotional data: STAIC (anxiety) and CDI (depression). These variables are considered to influence QOL and are associated with the concept (Annett et al. 2001; De Maso et al. 2004; Padua et al. 2006; Tsao et al. 2007; Wood et al. 2008; Zeller and Modi 2006). Each correlation was measured with Bravais-Pearson r. Sensitivity was assessed by studying the association of sociodemographic variables with ISQV-E scores. Socio demographic variables were: gender, age, having to redo level at school, social network, place of residence, type of home and family composition. There will be no significant difference according to age (e.g. GaynalTaminh et al. 2005), but we expected that significant difference may appear with family 
composition (Varni et al. 1999). For the other variables, no hypothesis can be formulated. Depending on the number of groups for the independent variables, the Student t test (2 groups) or analyses of variance (ANOVAs; more than 2 groups) were chosen.

All statistical analyses were done with Statistica 7.0. For all analyses, the level of significance was $p<.05$.

\section{Results}

The final sample included 288 children with a mean age of 10 years and 5 months. The sample consisted of 84 French children (29\%) and 204 Belgian children (71\%), 116 boys (40\%) and 172 girls $(60 \%)$.

Most of the children live in a house $(n=239 ; 83 \%)$ with a relative balance urban environment $(n=129 ; 45 \%)$-rural environment $(n=159 ; 55 \%)$. Many children ( $n=217 ; 76 \%)$ live with their parents (and their siblings). $32(11,1 \%)$ are only children, $35(11 \%)$ have a medical follow-up, $35(11 \%)$ repeated a year at school and $74(25 \%)$ have between 0 and 5 friends.

The validation study is centred on state, goal, rank and gap scores of the ISQV-E.

Descriptive data concerning the 20 items and the global score for the 288 children are presented in Table 1.

Table 1 Mean and standard deviation ISQV-E scores (state, goal, rank and gap for the 20 items and the global score) for the 288 children

\begin{tabular}{|c|c|c|c|c|c|}
\hline & & ISQV-E State & ISQV-E Goal & ISQV-E Rank & ISQV-E Gap \\
\hline 1. Sleep & 288 & $28.90(17.75)$ & $14.44(10.12)$ & $1.65(0.45)$ & $3.52(5.94)$ \\
\hline 2. Food & 288 & $21.21(16.47)$ & $14.12(10.92)$ & $1.65(0.46)$ & $1.71(3.85)$ \\
\hline 3. Pain & 288 & $32.76(23.61)$ & $14.40(12.84)$ & $1.04(0.63)$ & $3.07(6.78)$ \\
\hline 4. Health & 288 & $22.41(19.97)$ & $10.37(10.75)$ & $1.74(0.46)$ & $3.36(7.55)$ \\
\hline 5. Clothes & 288 & $14.96(13.90)$ & $10.22(11.52)$ & $1.20(0.56)$ & $0.63(2.32)$ \\
\hline 6. Physical appearance & 288 & $26.95(21.66)$ & $13.23(11.22)$ & $1.24(0.55)$ & $3.09(7.89)$ \\
\hline 7. Bedroom & 288 & $16.89(16.21)$ & $10.07(9.77)$ & $1.32(0.55)$ & $1.04(3.57)$ \\
\hline 8. Relations with grandparents & 282 & $14.13(16.15)$ & $9.09(10.44)$ & $1.70(0.45)$ & $1.28(4.23)$ \\
\hline 9. Relations with mother & 287 & $8.89(11.38)$ & $6.08(8.18)$ & $1.79(0.42)$ & $0.60(2.56)$ \\
\hline 10. Relations with father & 284 & $14.45(18.46)$ & $7.50(10.33)$ & $1.74(0.45)$ & $1.82(5.06)$ \\
\hline 11. Relations with siblings & 260 & $25.65(23.49)$ & $11.59(12.60)$ & $1.55(0.54)$ & $3.36(6.29)$ \\
\hline 12. Relations with friends & 288 & $18.40(19.64)$ & $9.03(9.28)$ & $1.51(0.48)$ & $1.81(5.62)$ \\
\hline $\begin{array}{l}\text { 13. Opinion people around me have } \\
\text { about me }\end{array}$ & 288 & $24.41(21.94)$ & $11.97(11.20)$ & $1.26(0.55)$ & $1.94(3.92)$ \\
\hline 14. School & 288 & $22.78(20.73)$ & $12.50(12.25)$ & $1.59(0.52)$ & $2.33(5.26)$ \\
\hline 15. School results & 288 & $20.63(20.09)$ & $8.78(9.24)$ & $1.68(0.47)$ & $2.95(6.92)$ \\
\hline 16. Sports activities & 278 & $16.27(19.07)$ & $9.93(10.91)$ & $1.46(0.52)$ & $1.28(3.90)$ \\
\hline 17. Extracurricular activities & 242 & $20.86(21.50)$ & $11.73(10.94)$ & $1.21(0.55)$ & $1.64(4.53)$ \\
\hline 18. Autonomy & 288 & $19.27(17.86)$ & $11.10(10.85)$ & $1.44(0.55)$ & $1.38(3.15)$ \\
\hline 19. Obedience to authority & 288 & $19.97(18.14)$ & $11.34(11.99)$ & $1.53(0.49)$ & $1.75(3.50)$ \\
\hline 20. Tolerance of frustration & 287 & $31.10(21.96)$ & $15.11(13.39)$ & $1.29(0.55)$ & $3.00(7.07)$ \\
\hline ISQV-E Global & 288 & $21(10.04)$ & $11.1(7.10)$ & $1.48(0.31)$ & $2.1(2.04)$ \\
\hline
\end{tabular}




\subsection{Applicability}

The duration of the whole protocol varied from 35 to $45 \mathrm{~min}$, with a mean time of $25 \mathrm{~min}$ for the ISQV-E. The ISQV-E was very well accepted. Missing data (Table 1) did not correspond to refusals but applied to questions that did not concern the child (example: relations with siblings for an only child). No child who had agreed to do the task asked to interrupt it. They like the playful nature of the questionnaire.

\subsection{Reliability}

Cronbach's alpha coefficients are 0.86 for the state score, 0.92 for the goal score, 0.92 for the rank score and 0.71 for the gap score.

The intercorrelations between the state score and the gap $(r=0.63 ; p<0.01)$ and goal $(r=0.64 ; p<0.01)$ scores is something that was expected since the child's "actual condition" will affect therefore the gap (Table 2). The other correlations between the different indices are below or equal to 0.20, indicating a weak association (small effect size) between these indices and supporting that goal, gap and rank scores measure specific and separate concepts.

\subsection{Factor Validity}

The number of subjects was adequate to conduct factorial analysis. No satisfactory factor analysis was found for the gap score (QoL score). The scree test (Fig. 4) showed a single factor. This result is strengthened by the relatively low correlations between the various items. Only five correlation coefficient on 190 have a value superior to 0.40: pain-health (0.56), pain-clothes $(0.45)$, mother-father (0.41), physical appearance-siblings $(0.41)$ and school-tolerance in the frustration $(0.42)$.

\subsection{Convergent Validity}

State, goal and gap ISQV-E scores are negatively and significantly correlated with the AUQUEI mean score (Table 3). The poorer the current state is (high state score), the poorer the QoL is (low AUQUEI score). Lower goals (greater distance from the ideal) are associated to poorer QoL (low AUQUEI score) is. The poorer the QoL (large gap score) is, the poorer the QoL (low AUQUEI score) is. Rank score is positively and significantly correlated with the AUQUEI score (Table 2). A high rank score (many items considered essential or very important) is associated to higher QoL (high AUQUEI score).

Table 2 Inter-correlations between the ISQV-E ${ }^{\odot}$ scores (state, goal, rank, gap)

\begin{tabular}{lllll}
\hline & ISQV-E $^{\odot}$ state & ISQV-E $^{\odot}$ goal & ISQV-E $^{\odot}$ rank & ISQV-E $^{\odot}$ gap $^{-}$ \\
\hline ISQV-E $^{(}$state & $/$ & 0.64 & -0.11 & 0.63 \\
& & $p<0.01$ & $p=0.07$ & $p<0.01$ \\
ISQV-E $^{(}$goal & $/$ & -0.20 & -0.07 \\
& & $p<0.005$ & $p=0.21$ \\
ISQV-E $^{(}$rank & & $/$ & $0 p 13$ \\
ISQV-E $^{(}$gap & & & $p<0.05$ \\
\hline
\end{tabular}




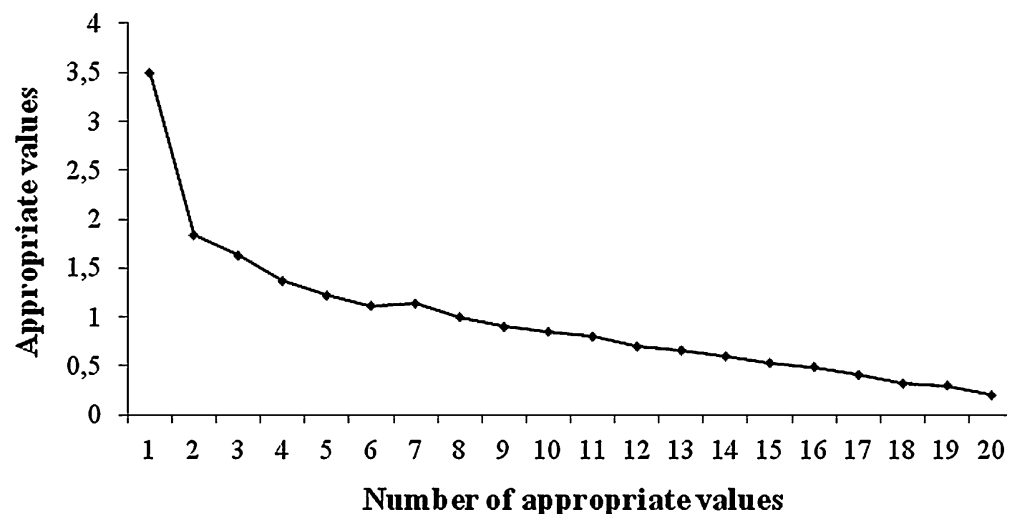

Fig. 4 Scree test for all 20 items of ISQV-E gap scores (QOL scores)

Table 3 Correlations between the ISQV-E (state, goal, rank and gap scores) and other tools (AUQUEI, STAIC and CDI)

\begin{tabular}{llllll}
\hline & $n$ & ISQV-E state & ISQV-E goal & ISQV-E rank & ISQV-E gap \\
\hline AUQUEI & \multirow{2}{*}{146} & -0.47 & -0.32 & 0.26 & -0.24 \\
& & $p<0.001$ & $p<0.001$ & $p<0.005$ & $p<0.005$ \\
STAIC & \multirow{2}{*}{288} & 0.30 & 0.25 & -0.15 & 0.15 \\
& & $p<0.001$ & $p<0.001$ & $p<0.05$ & $p<0.05$ \\
CDI & \multirow{2}{*}{288} & 0.60 & 0.15 & -0.08 & 0.57 \\
& & $p<0.01$ & $p<0.01$ & $p=0.16$ & $p<0.01$ \\
\hline
\end{tabular}

State, goal and gap ISQV-E scores are positively and significantly correlated with the STAIC and CDI mean scores (Table 3). The higher the level of state anxiety or depression, the poorer the actual state (large state score), the goal (large goal score) and the QoL (large gap score) are. Rank score is negatively and significantly correlated with the STAIC mean score (Table 3). Higher level of state anxiety is associated with lower rank score (more items at the level of "important" and "of moderately important"). From a descriptive point of view, it seems that the state score is the most strongly correlated with the STAIC and CDI data. Finally, the strongest correlations are observed between ISQV-E and CDI scores.

\subsection{Sensitivity}

Socio-demographic variables are significantly associated to ISQV-E scores particularly on the gap scores (QoL scores). For these scores, only the "siblings" variable has a $p>.1$. The parents' civil status $[\mathrm{F}(1,282)=5.7, p=0.004]$ and the social support the child receives $[\mathrm{F}(1,285)=3.1, p=0.048]$ are associated to QoL scores: children whose parents are separated have a significantly lower QoL than those whose parents are married [planned comparisons; $\mathrm{F}(1,282)=10.67, p=.001]$ or divorced $[\mathrm{F}(1,282)=8.54$, $p=.004$ ], and children who have $<6$ friends have a significantly lower QoL than those with $6-15$ friends $[\mathrm{F}(1,285)=6.54, p=.01]$. Living in an apartment $(t=2.4, p=0.02)$ and repeating a year at school $(t=2.2, p=0.03)$ are independently associated with a poorer QoL. There is a cultural difference: Belgian children have a better QoL than French children $(t=3.2, p=0.002)$. Age is not significantly correlated with ISQV-E scores. 
School year is only correlated with the rank score $(r=0.14, p=.02)$ : older the children used more higher rank of priority. However, we have to be cautious about this result because of the weak correlation.

\section{Discussion}

Overall, these results demonstrate the value and feasibility of the ISQV-E. They also establish that this new questionnaire possesses good psychometric qualities. Means and standard deviation provided in this article should not be considered as normative data considering the small sample size. The internal consistency of the four scores (state, goal, rank and gap) is satisfactory. The weak intercorrelations between them demonstrate that none of them can be substituted for another one: all scores have their own specificity. The data show the convergent validity and sensitivity of the ISQV-E. On the other hand, no satisfactory factorial structure was found although a multidimensional theoretical perspective was applied.

The first aim of this article was to study the feasibility of a self-assessment questionnaire of child QOL measuring alpha, beta and gamma changes.

This choice of self-assessment determined the theoretical threshold age below which it did not seem possible to obtain valid answers from children. In the view of Manificat and Dazord (1997), it is only at 7 or 8 years old that children become able to judge a set of similar situations and bring out the mean emotional tone. Before that age, the point of view expressed by the child is clearly situated in the present moment. The existence of an upper limit (12 years) takes developmental specificity (content, material, etc.) into consideration. Regarding the content of items, the investigation of certain domains such as sexuality seems unnecessary before adolescence (Harding 2001). The importance of other domains such as parents, close relations and family life predominates for the youngest children whereas peers have the most influence for adolescents (Titman et al. 1997). In the proposed scale, the color gradation within the VAS, the presence of faces expressing different emotional states, the pictorial representations of items, etc., are specifically adapted to children. The confrontation of these theoretical elements with reality showed satisfactory results. In other words, the applicability of the questionnaire for children from 8 to 12 years old appeared very good. This can be discussed at two different levels: content and material.

From the point of view of content, the majority of the children had no difficulties understanding the instructions. No child who had agreed to participate in the study wanted to drop out. All answered the various items, except the irrelevant ones. Only the "extracurricular activities" item needs to be reworked. Initially, the children focused only on musical, artistic or activities done in formal youth associations. From the point of view of the material (and its presentation), the questionnaire appeared to be much appreciated and the fact that the children were actors in the evaluation process contributed to their interest and involvement. Many children showed a desire to go beyond the simple transmission of data and beyond the test itself and to talk more freely their situation. So, like the AUQUEI and, more recently, the KidlQol (Gayral-Taminh et al. 2005a, b), the ISQV-E seems to be useful in contexts of psychological or social problems.

Our second aim was to determine the psychometric properties of this new child QoL questionnaire. In addition to the property of applicability already discussed above in relation to the tool's feasibility, the qualities of reliability, validity and sensitivity were analyzed. 
The internal consistency reliability of ISQV-E is satisfactory for the four global scores: all Cronbach's alpha coefficients have a value superior to 0.70 (Varni et al. 2002). The respective Cronbach's alphas (state $=0.86$, goal $=0.92$, rank $=0.92$, gap $=0.71$ ) are clearly superior to those of the EHRQL (Theunissen et al. 1998; Varni et al. 2005), the only child QoL questionnaire that uses a gap score. Eiser et al. (1999) obtained Cronbach's alphas of 0.62 (state), 0.69 (goal) and 0.50 (gap). The order of the values is similar to that of the values in this study: the highest Cronbach's alpha is observed for the goal score and the lowest for the gap score.

The validity of the ISQV-E can be assessed in two ways: factorial validity and convergent validity. The principal components analysis (with Varimax rotation), used to determine factorial validity, did not reveal a satisfactory factorial structure for the gap scores (QoL scores). This lack of factorial structure cannot be compared with the EHRQL because Eiser et al. (1999) did not do a factorial analysis. This result consolidates our hypothesis: a QoL evaluation in terms of gap between current state and goal, weighted by each item's speed of improvement or deterioration and its rank, imposes a limit on the number of items, primarily to respect the children's attention capacities. The small total number of items ( 20 for the current version of the questionnaire) does not allow one to ask several questions about a single domain, especially if all the aspects of the children's everyday life must be assessed. This explanation is similar to the comments of Eiser et al. (1999) and is confirmed by the results of Rajmil et al. [59], which did a qualitative analysis of the content of published generic QoL instruments for children and adolescents. They analyzed the dimensions and the items of each questionnaire on the basis of the three main QoL domains: physical, psychological and social. Based on this information, they created five categories in the physical domain (capacity for effortful activity, limitation of everyday activities, physical symptoms, beliefs or feelings about physical health and physical sensations, acute and chronic disorders), five categories in the psychological domain (negative feelings, positive feelings, self-esteem/body image, cognitive functioning, general behavior) and three categories in the social domain (friends, school, family/ home). Most of these categories (each consisting of several items) correspond to items in the ISQV-E. In other words, most items in the ISQV-E represent individual categories for Rajmil et al. (2004). Thus, the ISQV-E appears to consist of items that are relatively independent from each other, which is confirmed by the weak intercorrelations between the items. However, the Cronbach's alphas, as discussed above, show that all the items belong to the same overall concept: QoL. They form a coherent set that could not be improved by the removal of one or more items.

An alternative strategy to the factor analysis would be to ask experts in the field to classify the items into various domains based on their contents. Another would be to ask a group of children to classify them in the same way. On the basis of these classifications, the Cronbach's alpha coefficients would be calculated. However, working by domains would, for example, entail grouping relations with the mother, father and siblings in a single domain (family life), although a given child might have good relations with his mother and siblings but not with his father. To confirm this hypothesis, it might be interesting to do a factorial analysis with a questionnaire similar to the ISQV-E, but with different items. All the expressed items would concern specific dimensions as is the case with the PedsQL (Varni et al. 2001), for example. This questionnaire consists of four dimensions including a certain number of items logically associated with each dimension. For example, one of the dimensions is "feelings" and the items are "I feel sad or blue," "I have trouble sleeping" ...

The convergent validity appears to have been proven. The significant correlations between scores on the ISQV-E and the AUQUEI demonstrate the existence of 
convergence, but the value of these correlations indicates that the ISQV-E and the AUQUEI do not measure exactly the same thing. Not unexpectedly, the strongest correlation is found between the two state scores (ISQV-E state and AUQUEI). The significant correlations between the ISQV-E scores and the STAIC and CDI scores demonstrate the association between QoL and emotional data. Their existence confirms the results of other studies (Annett et al. 2001; De Maso et al. 2004; Padua et al. 2006; Tsao et al. 2007; Wood et al. 2008; Zeller and Modi 2006). When depression or anxiety scores go up, so do the ISQV-E state, goal and gap scores. These associations were anticipated because the ISQV$\mathrm{E}$ is based on qualitative measures of satisfaction and emotion, like the AUQUEI (Manificat and Dazord 1997) and KidlQol (Gayral-Taminh et al. 2005a, b). However, the link between these tests is not sufficient to conclude that the new QOL measure is superfluous: the tests refer to different theoretical constructs.

The sensitivity of the ISQV-E is good, particularly for the gap score (QoL score): taken separately, having separated parents, living in an apartment, having repeated a grade, and having few friends are all associated with a worse QoL. There is also a degree of cultural sensitivity: the French children have a worse QoL than the young Belgians. On the other hand, there is no significant link between QoL and age or between QoL and gender. This lack of sensitivity for the "age" and "gender" variables also exists for other self-report QoL questionnaires such as the KidlQol (Gayral-Taminh et al. 2005a, b) and the EHRQL (Eiser et al. 2001a, b). The AUQUEI, though, finds age sensitivity (Manificat and Dazord 1997; Manificat et al. 1997), but this result applies to particular items and not a global score. One potential explanation of the absence of sensitivity for age and gender could be the structure of the various QoL tools and particularly of the ISQV-E: it was developed to deal with developmental specificity, which implies an evaluation centered on a specific population, namely children between 8 and 12 years old.

\section{Conclusion}

This study had two main aims: to study the feasibility and interest of a new self-report child QoL questionnaire measuring alpha, beta and gamma changes and to determine the psychometric properties of this tool.

In view of the results obtained with 288 children, the applicability of the ISQV-E with 8-12 aged children seems clearly demonstrated and further utilization this new tool should be interesting in contexts of physical, psychological or social problems. Because this questionnaire has pictures for each item and is intended for children from 8 to 12 years old, it takes developmental specificity into account. The ISQV-E fits into the current research stream focusing on the subjectivity of the QoL concept. Moreover, it supplies qualitative measures of satisfaction and emotion while it is based on a clearly developed theoretical structure (Dupuis et al. 1989), which is quite rare (Davis et al. 2006). Both children's priorities and their adaptability are integrated into the evaluation of their QoL; this is what gives the ISQV-E its clinical originality, which is strengthened by the tool's modular approach. This modular approach allows for the design of up to 6 new items to capture the specificity of particular groups like oncology, neglected kids, etc.

The validation study was promising: the ISQV-E proved to be applicable, sensitive, reliable and valid. However, certain points such as test-retest reliability remain to be studied and the others, such as the absence of a satisfactory factorial structure, need to be examined again. 


\section{References}

Allison, P. J., Locker, D., \& Feine, J. S. (1997). Quality of life: A dynamic construct. Social Science and Medicine, 45(2), 221-230.

Annett, R. D., Bender, B. G., Lapidus, J., DuHamel, T. R., \& Lincoln, A. (2001). Predicting children's quality of life in an asthma clinical trial: What do children's report tell us? Journal of Pediatrics, 139(6), 854-861.

Ashby, W. R. (1956). An introduction to cybernetics. London: Methuens (1979 Edition).

Baars, R. M., Atherton, C. I., Koopman, H. M., Bullinger, M., \& Power, M. (2005). The European DISABKIDS project: Development of seven condition-specific modules to measure health related quality of life in children and adolescents. Health and Quality of Life Outcomes, 3, 70.

Bertalanffy, L. (1973). Théorie Générale des Systèmes. Paris: Dunod.

Blanchon, Y. C. (1997). Editorial: La qualité de vie de l'enfant est-elle mesurable? Neuropsychiatrie Enfance et Adolescence, 45(3), 99-100.

Bruil, J. (1999). Development of a quality of life instrument for children with a chronic illness. Doctoral thesis. University of Leiden.

Bullinger, M., \& Ravens-Sieberer, U. (1995). Evaluation de qualité de vie des enfants: Revue de littérature. Revue Européenne de Psychologie Appliquée, 45(4), 255-256.

Calaminus, G., Weinspach, S., Teske, C., \& Göbel, U. (2000). Quality of life in children and adolescents with cancer. First results of an evaluation of 49 patients with the PEDQOL questionnaire. Klinische Pädiatrie, 212(4), 211-215.

Calman, K. C. (1984). Quality of life in cancer patients - an hypothesis. Journal of Medical Ethics, 10, 124127.

Connolly, M. A., \& Johnson, J. A. (1999). Measuring quality of live in paediatric patients. Pharmacoeconomics, 16(6), 605-625.

Czyzewski, D. I., Mariotto, M. J., Bartholomew, L. K., LeCompte, S. H., \& Sockrider, M. M. (1994). Measurement of quality of well being in a child and adolescent cystic fibrosis population. Medical Care, 32, 965-972.

Davis, E., Waters, E., Mackinnon, A., Reddihough, D., Graham, H. K., Mehmet-Radji, O., et al. (2006). Paediatric quality of life instruments: A review of the impact of the conceptual framework on outcomes. Developmental Medicine and Child Neurology, 48(4), 311-318.

De Maso, D. R., Lauretti, A., Spieth, L., Van Der Feen, J. R., Jay, K. S., Gauvreau, K., et al. (2004). Psychosocial factors and quality of life in children and adolescents with implantable cardioverterdefibrillators. American Journal of Cardiology, 93, 582-587.

Dupuis, G., Perrault, J., Lambany, M.-C., Kennedy, E., \& David, P. (1989). A new tool to assess quality of life: The quality of life systemic inventory. Quality of Life and Cardiovascular Care, 5, 36-45.

Dupuis, G., Taillefer, M.-C., Etienne, A.-M., Fontaine, O., Boivin, S., \& Von Turk, A. (2000). Measurement of quality of life in cardiac rehabilitation. In J. Jobin, F. Maltais, P. LeBlanc, C. Simard, \& H. Kinetics (Eds.), Advances in cardiopulmonary rehabilitation (pp. 247-273). Champaign, IL: Human Kinetics.

Duquette, R., Dupuis, G., \& Perrault, J. (1994). A new approach for quality of life assessment in cardiac patients: Rationale and validation of the quality of life systemic inventory. The Canadian Journal of Cardiology, 10(1), 106-112.

Eiser, C. (1997). Children's quality of life measures. Archives of Disease in Childhood, 77(4), 350-354.

Eiser, C., \& Jenney, M. (2007). Measuring quality of life. Archives of Disease in Childhood, 92, 348-350.

Eiser, C., \& Morse, R. (2001a). A review of measures of quality of life for children with chronic illness. Archives of Disease in Childhood, 84, 205-211.

Eiser, C., \& Morse, R. (2001b). Can parents rate their child's health-related quality of life? Results of a systematic review. Quality of Life Research, 10, 347-357.

Eiser, C., \& Morse, R. (2001c). The measurement of quality of life in children: Past and future perspectives. Journal of Developmental and Behavioral Pediatrics, 22(4), 248-256.

Eiser, C., Cotter, I., Oades, P., Seamark, D., \& Smith, R. (1999). Health-related quality of life measures for children. International Journal of Cancer, 12(Suppl), 87-90.

Eiser, C., Vance, Y. H., \& Seamark, D. (2000). The development of a theoretically generic measure of quality of life for children aged 6-12 years: A preliminary report. Child: Care, Health and Development, 26(6), 445-456.

Flapper, B. C., Koopman, H. M., Ten, N. C., \& van-der Schans, C. P. (2006). Psychometric properties of the TACQOL-asthma, a disease-specific measure of health related quality-of-life for children with asthma and their parents. Chronic Respiratory Disease, 3(2), 65-72. 
Fluchel, M., Horsman, J. R., Furlong, W., Castillo, L., Alfonz, Y., \& Barr, R. D. (2008). Self and proxy reported health status and health-related quality of life in survivors of childhood cancer in Uruguay. Pediatric Blood \& Cancer, 50, 838-843.

Gayral-Taminh, M., Bravi, C., Depond, M., Pourre, F., Maffre, T., Raynaud, J. P., et al. (2005a). Autoévaluation de la qualité de vie d'enfants de 6 à 12 ans: Analyse du concept et élaboration d'un outil prototype. Santé Publique, 17(1), 35-45.

Gayral-Taminh, M., Matsuda, T., Bourdet-Loubère, S., Lauwers-Cances, V., Raynaud, J. P., \& Grandjean, H. (2005b). Auto-évaluation de la qualité de vie d'enfants de 6 à 12 ans: Construction et premières étapes de validation du KidlQol, outil générique présenté sur ordinateur. Santé Publique, 17(2), 167177.

Georges, G., \& Vera, L. (1999). La timidité chez l'enfant et l'adolescent. Paris: Dunod.

Golembiewski, R., Billingsley, K., \& Yeager, S. (1976). Measuring change and persistence in human affairs: Types of change generated by OD designs. The Journal of Applied Behavioral Science, 12(2), 133157.

Harding, L. (2001). Children's quality of life assessments: A review of generic and health related quality of life measures completed by children and adolescents. Clinical Psychology and Psychotherapy, 8, 7996.

Herdman, M., Rajmil, L., Ravens-Sieberer, U., Bullinger, M., Power, M., \& Alonso, J. (2002). Expert consensus in the development of a European health-related quality of life measure for children and adolescents: A Delphi study. Acta Paediatrica, 91, 1385-1390.

Kovacs, M., \& Beck, A. T. (1977). An empirical clinical approach towards definition of childhood depression. In J. G. Sculterbrandt \& A. Raskin (Eds.), Depression in childhood: Diagnosis, treatment and conceptual models (pp. 1-25). New York: Raven Press.

Levi, R., \& Drotar, D. (1998). Critical issues and needs in health quality of life assessment of children and adolescents with chronic health conditions. In D. Drotar (Ed.), Measuring health-related quality of life in children and adolescents (pp. 3-24). London: Lawrence Erlbaum.

Mack, C., \& Morr, L. (1982). Versions françaises d'échelles d'évaluation de la dépression: Les échelles CDI et ISC de Maria Kovacs. Neuropsychiatrie de l'Enfance, 30(10-11), 627-652.

Maes, S., \& Bruil, J. (1995). Assessing quality of life of children with a chronic illness. In J. RodriguezMarin (Ed.), Health psychology and quality of life research. Proceedings of the 8th annual conference of the European health psychology society, Vol. II. (pp. 637-652). University of Alicante: Spain.

Manificat, S., \& Dazord, A. (1997). Evaluation de la qualité de vie de l'enfant: Validation d'un questionnaire, premiers résultats. Neuropsychiatrie Enfance et Adolescence, 45(3), 106-114.

Manificat, S., Dazord, A., Cochat, P., \& Nicolas, J. (1997). Evaluation de la qualité de vie en pédiatrie: Comment recueillir le point de vue de l'enfant. Archives Pédiatrie, 4(12), 1238-1246.

Matza, L. S., Swensen, A. R., Flood, E. M., Secnik, K., \& Leidy, N. K. (2004). Assessment of health related quality of life in children: A review of conceptual, methodological, and regulatory issues. Value in Health, 7(1), 79-92.

Michalos, A. C. (1985). Multiple discrepancies theory. Social Indicators Research, 16(4), 347-417.

Missotten, P., Etienne, A.-M., \& Dupuis, G. (2007). La qualité de vie infantile: état actuel des connaissances. Revue Francophone de Clinique Comportementale et Cognitive, 12(4), 16-27.

Nathan, P. C., Furlong, W., \& Barr, R. D. (2004). Challenges to the measurement of health-related quality of life in children receiving cancer therapy. Pediatric Blood \& Cancer, 43(3), 215-223.

Padua, L., Aprile, I., Cavallaro, T., Commodari, I., La Torre, G., Pareyson, D., Quattrone, A., Rizzuto, N., Vita, G., Tonali, P., \& Schenone, A. for the Italian CMT QoL Study Group (2006). Variables influencing quality of life and disability in Charcot Marie Tooth (CMT) patients: Italian multicentre study. Neurological Sciences, 27, 417-423.

Powers, W. T. (1973). Behavior: The control of perception. Chicago: Aldine.

Raat, H., Mohangoo, A. D., \& Grootenhuis, M. A. (2006). Pediatric health-related quality of life questionnaires in clinical trials. Current opinion in Allergy and Clinical Immunology, 6(3), 180-185.

Rajmil, L., Herdman, M., Fernandez de Sanmamed, M. J., Detmar, S., Bruil, J., Ravens-Sieberer, U., et al. (2004). Generic health-related quality of life instruments in children and adolescents: A qualitative analysis of content. Journal of Adolescent Health, 34(1), 37-45.

Ravens-Sieberer, U., Erhart, M., Wille, N., Wetzel, R., Nickel, J., \& Bullinger, M. (2006). Generic healthrelated quality of life assessment in children and adolescents: Methodological considerations. Pharmacoeconomics, 24(12), 1199-1220.

Ravens-Sieberer, U., Auquier, P., Erhart, M., Gosch, A., Rajmil, L., Bruil, J., et al. (2007). The KIDSCREEN-27 quality of life measure for children and adolescents: Psychometric results from a cross-cultural survey in 13 European countries. Quality of Life Research, 16(8), 1347-1356. 
Rebok, G., Riley, A., Forrest, C., Green, B., Robertson, J., \& Tambor, E. (2001). Elementary schoolaged children'reports of their health: A cognitive interviewing study. Quality of Life Research, 10(1), 59-70.

Rodary, C. (2000). Méthodologie d'étude de la qualité de vie chez l'enfant en recherche clinique. Archives de Pédiatrie, 7(suppl. 2), 230s-232s.

Schmidt, L. J., Garratt, A. M., \& Fitzpatrick, R. (2002). Child/parent-assessed population health outcome measures: A structured review. Child: Care, Health and Development, 28(3), 227-237.

Siméoni, M. C., Auquier, P., Delarozière, J. C., \& Béresniak, A. (1999). Evaluation de la qualité de vie chez l'enfant et l'adolescent. La Presse Médicale, 28(19), 1033-1039.

Speyer, E., Herbinet, A., Vuillemin, A., Chastagner, P., \& Briançon, S. (2009). Agreement between children with cancer and their parents in reporting the child's health-related quality of life during a stay at the hospital and at home. Child: Care, Health and Development, 35(4), 489-495.

Spielberger, C. D., Edwards, C. D., Lushene, R. E., Montuori, J., \& Platzek, D. (1973). State-trait anxiety inventory for children ("How I feel questionnaire"): Professional manual. Redwood, CA: Mind Garden.

Spieth, L. E., \& Harris, C. V. (1996). Assessment of health related quality of life in children and adolescents: An integrative review. Journal of Pediatric Psychology, 21, 175-193.

Tabachnick, B. G., \& Fidell, L. S. (2001). Computer-assisted research design and analysis. Boston: Allyn and Bacon.

Theunissen, N. C., Vogels, T. G., Koopman, H. M., Verrips, G. H., Zwinderman, K. A., Verloove-Vanhorick, S. P., et al. (1998). The proxy problem: Child report versus parent report in health-related quality of life research. Quality of Life Research, 7(5), 387-397.

Titman, P., Smith, M., \& Gragam, P. (1997). Assessment of the quality of life of children. Clinical Child Psychology and Psychiatry, 2(4), 597-606.

Tsao, J. C., Meldrum, M., Kim, S. C., \& Zeltzer, L. K. (2007). Anxiety sensitivity and health-related quality of life in children with chronic pain. The Journal of Pain, 8(10), 814-823.

Varni, J. W., Seid, M., \& Rode, C. A. (1999). The PedsQL: Measurement model for the pediatric quality of life inventory. Medical Care, 37, 126-139.

Varni, J. W., Seid, M., \& Kurtin, P. (2001). PedsQL 4.0: Reliability and validity of the pediatric quality of life inventory version 4.0 generic core scales in healthy and patient populations. Medical Care, 39(8), 800-812.

Varni, J. W., Burwinkle, T. M., Katz, E. R., Meeske, K., \& Dickinson, P. (2002a). The PedsQL in pediatric cancer: Reliability and validity of the pediatric quality of life inventory generic core scales, multidimensional fatigue scale, and cancer module. Cancer, 94(7), 2090-2106.

Varni, J. W., Seid, M., Smith Knight, T., Burwinkle, T., Brown, J., \& Szer, I. S. (2002b). The PedsQL in pediatric rheumatology. Reliability, validity, and responsiveness of the pediatric quality of life inventory generic core scales and rheumatology module. Arthritis and Rheumatism, 46(3), 714-725.

Varni, J. W., Burwinkle, T., Seid, M., \& Skarr, D. (2003). The PedsQL 4.0 as a pediatric population health measure: Feasibility, reliability, and validity. Ambulatory Pediatrics, 3(6), 329-341.

Varni, J. W., Burwinkle, T. M., Rapoff, M. A., Kamps, J. L., \& Olson, N. (2004a). The PedsQL in pediatric asthma: Reliability and validity of the pediatric quality of life. Inventory generic core scales and asthma module. Journal of Behavioral Medicine, 27(3), 297-318.

Varni, J. W., Sherman, S., Burwinkle, T., Dickinson, T. E., \& Dixon, P. (2004b). The PedsQL family impact module: Preliminary reliability and validity. Health and Quality of Life Outcomes, 2(1), 55.

Varni, J. W., Burwinkle, T. M., \& Lane, M. M. (2005). Health-related quality of life measurement in pediatric clinical practice: An appraisal and precept for future research and application. Health and Quality of Life Outcomes, 3(34), 1-13.

Wallander, J. L., Schmitt, M., \& Koot, H. M. (2001). Quality of life measurement in children and adolescents: Issues, instruments and applications. Journal of Clinical Psychology, 57(4), 571-585.

Weiner, N. (1948). Cybernetics. New Tork: John Wiley.

WHOQOL Group (Geneva). (1993). Study protocol for the World Health Organization project to develop a quality of life assessment instrument (WHOQOL). Quality of Life Research, 2, 153-159.

Wood, L. J., Sherman, E., Hamiwka, L. D., Blackman, M., \& Wirrell, E. (2008). Depression, anxiety, and quality of life in siblings of children with intractable epilepsy. Epilepsy \& Behavior, 13, 144-148.

Yeh, C. H., Chang, C. W., \& Chang, P. C. (2005). Evaluating quality of life in children with cancer using children's self-reports and parent-proxy reports. Nursing Research, 54, 354-362.

Zeller, M. H., \& Modi, A. C. (2006). Predictors of health-related quality of life in obese youth. Obesity, 14(1), 122-130. 